\title{
Acute febrile illness is associated with Rickettsia spp infection in dogs
}

\author{
Laia Solano-Gallego ${ }^{1,2^{*}}$, Alessandra Capri ${ }^{3,4}$, Maria Grazia Pennisi ${ }^{4}$, Marco Caldin ${ }^{5}$, Tommaso Furlanello ${ }^{5}$ \\ and Michele Trotta ${ }^{5}$
}

\begin{abstract}
Background: Rickettsia conorii is transmitted by Rhipicephalus sanguineus ticks and causes Mediterranean Spotted Fever (MSF) in humans. Although dogs are considered the natural host of the vector, the clinical and epidemiological significance of $R$. conorii infection in dogs remains unclear. The aim of this prospective study was to investigate whether Rickettsia infection causes febrile illness in dogs living in areas endemic for human MSF.

Methods: Dogs from southern Italy with acute fever $(n=99)$ were compared with case-control dogs with normal body temperatures $(n=72)$. Serology and real-time PCR were performed for Rickettsia spp., Ehrlichia canis, Anaplasma phagocytophilum/A. platys and Leishmania infantum. Conventional PCR was performed for Babesia spp. and Hepatozoon spp. Acute and convalescent antibodies to R. conorii, E. canis and A. phagocytophilum were determined.

Results: The seroprevalence rates at first visit for $R$. conorii, E. canis, A. phagocytophilum and L. infantum were $44.8 \%, 48.5 \%$, $37.8 \%$ and $17.6 \%$, respectively. The seroconversion rates for $R$. conorii, E. canis and A. phagocytophilum were $20.7 \%, 14.3 \%$ and $8.8 \%$, respectively. The molecular positive rates at first visit for Rickettsia spp., E. canis, A. phagocytophilum, A. platys, L. infantum, Babesia spp. and Hepatozoon spp. were 1.8\%, 4.1\%, 0\%, 2.3\%, 11.1\%, 2.3\% and 0.6\%, respectively. Positive PCR for E. canis (7\%), Rickettsia spp. (3\%), Babesia spp. (4.0\%) and Hepatozoon spp. (1.0\%) were found only in febrile dogs. The DNA sequences obtained from Rickettsia and Babesia PCRs positive samples were 100\% identical to the R. conorii and Babesia vogeli sequences in GenBank ${ }^{\circledR}$, respectively. Febrile illness was statistically associated with acute and convalescent positive $R$. conorii antibodies, seroconversion to $R$. conorii, E. canis positive PCR, and positivity to any tick pathogen PCRs. Fourteen febrile dogs (31.8\%) were diagnosed with Rickettsia spp. infection based on seroconversion and/or PCR while only six afebrile dogs (12.5\%) seroconverted $(P=0.0248)$. The most common clinical findings of dogs with Rickettsia infection diagnosed by seroconversion and/or PCR were fever, myalgia, lameness, elevation of C-reactive protein, thrombocytopenia and hypoalbuminemia.
\end{abstract}

Conclusions: This study demonstrates acute febrile illness associated with Rickettsia infection in dogs living in endemic areas of human MSF based on seroconversion alone or in combination with PCR.

Keywords: Dog, Febrile illness, Rickettsia conorii, Ehrlichia, Anaplasma, Babesia, Hepatozoon, Leishmania, Serology, PCR

\section{Background}

Rickettsia conorii is a Spotted Fever Group (SFG) Rickettsia that causes Mediterranean Spotted Fever (MSF) in humans in Mediterranean countries and Sub-Saharan Africa. The onset of MSF is abrupt and typical human cases present with high fever, flu-like symptoms, a black eschar at the

\footnotetext{
*Correspondence: laia.solano@uab.cat

1 Departament de Medicina i Cirurgia Animals, Facultat de Veterinària, Universitat Autònoma de Barcelona (UAB), Cerdanyola 08193, Barcelona, Spain

${ }^{2}$ Royal Veterinary College, University of London, Hatfield, United Kingdom Full list of author information is available at the end of the article
}

tick bite site and a maculo-papular rash. Severe forms of the disease may present with major neurological manifestations and multi-organ involvement may occur. The mortality rate is estimated at around $2.5 \%$ and classical risk factors for severe forms include elderly age, cirrhosis, chronic alcoholism and glucose-6-phosphate dehydrogenase deficiency [1,2]. In Italy, more than 1000 human cases of MSF are reported annually mainly in Sicily, Sardinia, Lazio and Liguria [2,3]. Moreover, a more pathogenic subspecies of $R$. conorii, $R$. conorii israelensis, has been described in human cases in Sicily [4]. In addition, $R$. conorii 
Indian tick typhus strain has also been diagnosed in human patients in Sicily [5].

The organism is transmitted in the Mediterranean basin by the brown dog tick Rhipicephalus sanguineus. Mediterranean spotted fever is a human seasonal disease that is frequently diagnosed between April and October with a maximum peak in June-August [2] and it is well correlated with the presence of $R h$. sanguineus. Ticks are possibly the main reservoir of $R$. conorii infection due to the existence of both transtadial and transovarial transmission and cofeeding in this tick sp. $[1,2,6]$. The role of dogs in maintaining zoonotic foci remains unclear [1]. Although dogs are the natural host of the vector, there is limited information on their susceptibility to Rickettsiae infection and on the development of long duration rickettsiemia able to allow transmission to a feeding vector tick [7]. However, experimental infections suggest that dogs can be competent reservoirs for $R$. conorii [6,7]. Due to high levels of $R h$. sanguineus exposure, dogs have been used in epidemiological studies as sentinels for human MSF [8] and proximity to seroreactive dogs has been found as a risk factor for MSF in humans [9]. Several studies have reported anti- $R$. conorii antibodies by the indirect fluorescent antibody test (IFA) in dogs in $R$. conorii endemic countries such as Italy with seroprevalence rates ranging from $15.5 \%$ to $74 \%$ [10]. The very high seroprevalences detected in Italian dogs would suggest frequent exposure to Rickettsia spp. or persistent low-grade infection with a rickettsial organism or organisms that cross react with $R$. conorii antigens by IFA testing.

Studies reported the detection of Rickettsia DNA in the blood of Spanish and Italian dogs [11-14]. However, evidence that natural $R$. conorii infection causes illness in dogs remains limited. Illness has been associated with $R$. conorii natural infection in only a few dogs since human MSF was described in 1910 [15]. The possibility that $R$. conorii may cause a clinical disease in dogs is supported by the evidence of seroconversion in three sick dogs from Israel [16] and the association between anemia and seroreactivity to $R$. conorii antigens [17]. In addition, a study reported the association between male dogs and seroreactivity to $R$. conorii antigens as found in humans where males have higher rates of infection $[2,17]$. Moreover, febrile illness has been associated with $R$. conorii infection in three dogs from Sicily by means of seroconversion and PCR [13] and in seven dogs from Portugal by PCR [18]. For this reason, the clinical significance of infection with $R$. conorii, or other SFG rickettsiae in dogs, remains unclear and requires further characterization.

The aims of this prospective case-control study were: 1) to investigate the presence of Rickettsia spp. infection in dogs from southern Italy (Sicily and Reggio Calabria) with fever by means of serological and molecular tests when compared with case control dogs with normal body temperatures; 2) to evaluate whether Rickettsia spp. infection causes clinical disease and clinicopathological abnormalities by clinical history, physical examination and baseline laboratory tests; and 3) to evaluate co-infections with other microorganisms that cause canine vector borne diseases such as Leishmania infantum, Ehrlichia spp., Anaplasma spp., Babesia spp. and Hepatozoon canis and their clinical importance in sick dogs.

\section{Methods \\ Dogs}

The study was carried out between August-November 2009 and between April-November 2010 in Sicily, Italy. Dogs were enrolled in the study from 20 Veterinary clinics throughout Sicily (Catania, Caltanissetta, Enna, Messina, Palermo, Siracusa and Trapani) and from the south of Calabria (Reggio Calabria).

Physical and laboratory examinations were performed during the study at the time of onset of clinical signs and after one month or later. MSF is most commonly described in humans with a maximum peak in June and August [2]. Clinical questionnaires were distributed and filled by veterinarians to obtain detailed clinical data at the time of onset of clinical signs and after one month or later. Information collected from the questionnaires included the date of sample collection, age, sex, breed, type of housing (indoor versus outdoor), flea and tick exposure, presence of vectors on clinical examination, vaccination status, presenting complaint, clinical signs observed, previous medical history, clinical response to specific therapy and clinical status of the dog's owner.

Blood serum samples were taken two times (first and second visit) when possible with an interval between samplings of one month in the majority of dogs or two months in few dogs, in order to evaluate acute (first visit) and convalescent (second visit) antibodies and seroconversion. Blood was taken in EDTA tubes at the time of diagnosis prior to doxycycline treatment and after one month or more. One hundred and seventy-one dogs were included in the study and they were divided into two groups: febrile dogs and afebrile dogs.

\section{Febrile dogs}

Ninety-nine dogs with febrile illness were enrolled in the study. The inclusion criteria were: 1) Dogs with an acute onset (less than 10 days of duration) of fever $\left(\geq 39.5^{\circ} \mathrm{C}\right)$ were included. 2) Only dogs with informed consent signed by the owner were enrolled. The exclusion criteria were: 1) Dogs with an acute onset of fever and evidence of another disease involved such as heat-stroke, neoplasia, bacterial abscesses and pyometra; 2) Dogs with a recent history of doxycycline administration during the past two months; 3) Dogs without signed informed consent by the owner. 


\section{Matched case afebrile dogs}

A case control set of dogs $(n=72)$ with no apparent disease or other diseases unrelated to febrile illness was randomly selected from dogs seen at the same veterinary clinics during the same month as the febrile dogs. The inclusion criteria were: 1) Healthy dogs evaluated for routine procedures such as vaccinations, elective surgery (neutering/spaying); 2 ) Sick dogs that did not present with acute fever $\left(\geq 39.5^{\circ} \mathrm{C}\right)$ or suspicion of tick-transmitted disease; 3) Only dogs with informed consent signed by the owner were enrolled in the study. The exclusion criteria were: 1) Dogs recently treated with doxycycline during the last two months; 2) Dogs without signed informed consent by the owner.

Only privately owned dogs were included in the study and examined by routine non-invasive diagnostic procedures. Owners were accurately informed and an informed consent was signed by both owner and veterinarian. Eight dogs presented clinical signs but not fever.

Blood samples from dogs were taken for diagnostic purposes as part of clinical management and, therefore, no ethical approval was needed.

Unfortunately, only 92 out of 171 dogs enrolled in the study came back for a second visit a month or more after the first visit.

\section{Laboratory procedures \\ Routine laboratory tests}

Complete blood count $(\mathrm{CBC})$ with blood smear examination and platelet concentration, complete biochemical profile including C-reactive protein and serum electrophoresis were performed in all dogs at the time of diagnosis and second visit as previously described [19]. The samples were submitted in less than 24 hours from blood withdrawal to Laboratorio Privato di Analisi Veterinarie San Marco (Padua, Italy). Whole EDTA blood and serum samples for PCR and serology were stored at $-20^{\circ} \mathrm{C}$ until used for molecular and serological testing.

\section{Serological techniques (IFA or ELISA)}

Indirect immunofluorescence assays (IFA) kits from Fuller Laboratories (Fullerton, CA, USA) were used for IgG antibodies detection against $R$. conorii, E. canis and $A$. phagocytophilum antigens following manufacturer's instructions.

IFA does not distinguish between canine antibodies against $A$. phagocytophilum and Anaplasma platys [20]. In addition, the IFA test used for Rickettsia conorii is known to cross-react with other species of spotted fever group Rickettsia such as $R$. rickettsii, $R$. helvetica, $R$. slovaca and $R$. massiliae as stated in manufacturer's instructions.

An antibody titer of 1:64 or greater was considered positive for $R$. conorii antigen. An antibody titer of 1:80 or greater was considered positive for $E$. canis and $A$. phagocytophilum antigens.
Seroconversion was defined as $\geq 2-4$ fold increase convalescent antibody titers (second visit) when acute (first initial visit) titers were positive or as any positive antibody titers when acute (first initial visit) titers were negative. High antibody titers were defined as equal or greater of 1:512 (R. conorii) or 1:640 (E. canis and A. phagocytophilum). Paired samples were run the same day.

ELISA was performed to detect antibodies against L. infantum as previously described [21].

\section{DNA extraction, real-time PCR for Rickettsia spp. and other infectious agents and DNA sequencing}

DNA extraction was performed from EDTAanticoagulated whole blood sample by the High Pure PCR Template Preparation Kit (Roche Applied Science, $\mathrm{GmbH}$, Mannheim, Germany) in accordance with the manufacturer's protocol with some modifications. Two hundred $\mu \mathrm{L}$ of blood were incubated with $40 \mu \mathrm{L}$ of Proteinase $\mathrm{K}$ and with $200 \mu \mathrm{L}$ of Binding Buffer at $72^{\circ} \mathrm{C}$ for $1 \mathrm{~h}$. Subsequent steps were carried out according to the manufacturer's instructions (Roche Applied Science, $\mathrm{GmbH}$, Mannheim, Germany). DNA was eluted in $50 \mu \mathrm{L}$ of elution buffer at $72^{\circ} \mathrm{C}$ [13].

A quantitative PCR (qPCR) for the detection of Rickettsia spp., A. phagocytophilum/A. platys, E. canis and L. infantum in DNA samples was performed. PCR amplifications were carried out for Rickettsia spp. [13,14], E. canis, A. phagocytophilum/A. platys (fragment of $16 \mathrm{~S}$ rRNA gene) [22], and L. infantum (fragment of kinetoplast minicircle) [23] using LCSet primers and probes following manufacturer's instructions (TIB MOLBIOL). Real-time PCR amplifications were carried out in Roche LightCycler, version 3.5.17, (Roche Diagnostic, GmbH, Mannheim, Germany), with a final volume of $10 \mu \mathrm{L}$, including $2.5 \mu \mathrm{L}$ of the DNA template, $2 \mu \mathrm{L}$ of Light Cycler Fast start reaction mix (FastStart DNA Master ${ }^{\text {PLUS }}$, Roche Diagnostic, GmbH, Mannheim, Germany), and $0.5 \mu \mathrm{L}$ of LCSet primers and probes according to the manufacturer's instructions (TIB Molbiol, Berlin, Germany). Amplifications were conducted in sealed $20 \mu \mathrm{L}$ Light Cycler glass capillaries (Roche Diagnostic, GmbH, Mannheim, Germany). Thermal cycling for Rickettsia spp qPCR comprised an initial denaturation step at $95^{\circ} \mathrm{C}$ for $8 \mathrm{~min}$, followed by 55 cycles of a denaturation at $95^{\circ} \mathrm{C}$ for $5 \mathrm{~s}$, annealing at $59^{\circ} \mathrm{C}$ for $7 \mathrm{~s}$, and extension at $72^{\circ} \mathrm{C}$ for $7 \mathrm{~s}$, with quantification of fluorescence signal $[13,14]$. Thermal cycling for A. phagocytophilum/A. platys qPCR comprised an initial denaturation step at $95^{\circ} \mathrm{C}$ for $8 \mathrm{~min}$, followed by 45 cycles of a denaturation at $95^{\circ} \mathrm{C}$ for $5 \mathrm{~s}$, annealing at $61^{\circ} \mathrm{C}$ for $10 \mathrm{~s}$, and extension at $72^{\circ} \mathrm{C}$ for $11 \mathrm{~s}$, with quantification of fluorescence signal [22]. Thermal cycling for $E$. canis qPCR comprised an initial denaturation step at $95^{\circ} \mathrm{C}$ for $8 \mathrm{~min}$, followed by 60 cycles of a denaturation at $95^{\circ} \mathrm{C}$ for $5 \mathrm{~s}$, annealing at $61^{\circ} \mathrm{C}$ for $10 \mathrm{~s}$, and extension at $72^{\circ} \mathrm{C}$ 
for $11 \mathrm{~s}$, with quantification of fluorescence signal [22]. Thermal cycling for Leishmania infantum qPCR comprised an initial denaturation step at $37^{\circ} \mathrm{C}$ for $10 \mathrm{~min}, 95^{\circ}$ $\mathrm{C}$ for $8 \mathrm{~min}$, followed by 45 cycles of a denaturation at $95^{\circ}$ $\mathrm{C}$ for $5 \mathrm{~s}$, annealing at $60^{\circ} \mathrm{C}$ for $5 \mathrm{~s}$, and extension at $72^{\circ} \mathrm{C}$ for $4 \mathrm{~s}$, with quantification of fluorescence signal [23]. A real-time PCR reaction was considered positive when the normalized fluorescence signal [ratio of the signal from detection channel F2 $(640 \mathrm{~nm})$ to the signal from detection channel F1 (495 nm) at the end of the annealing step] showed an exponential increase in fluorescence. The melting temperature of probe-template hybrids was automatically determined by the analysis of the software, and was useful for species identification of Rickettsia rickettsii versus other Rickettsia species and A. phagocytophilum versus $A$. platys. Rickettsia rickettsii had a melting temperature of approximately $65^{\circ} \mathrm{C}$, while $R$. conorii had a melting temperature of approximately $58.2^{\circ} \mathrm{C}$. Anaplasma phagocytophilum had a melting temperature of approximately $66^{\circ} \mathrm{C}$, while $A$. platys had a melting temperature of approximately $57^{\circ} \mathrm{C}$. Each real-time PCR run include a blank, a negative control, and a DNA cloned amplicon as a positive control (LCSet positive control; TIB Molbiol, Berlin, Germany).

Conventional PCRs for the detection of fragment of $18 \mathrm{~S}$ rRNA gene of Babesia spp. [24] and of $18 \mathrm{~S}$ rRNA gene of Hepatozoon spp. [25] were also carried out, as previously described. The partial $18 \mathrm{~S}$ rRNA gene for Babesia spp. was amplified by using conventional PCR analysis in a final volume of $50 \mu \mathrm{L}$, containing $2.5 \mu \mathrm{L}$ of DNA template from each sample, $1 \mu \mathrm{L}(10 \mathrm{pmol} / \mu \mathrm{l})$ of each of the primers, PIRO-A and PIRO-B, $1 \mu \mathrm{L}(10 \mathrm{pmol} / \mu \mathrm{l})$ of deoxyribonucleotide triphosphates (dNTPs) (Roche Diagnostics, GmbH, Mannheim, Germany), $5 \mu \mathrm{L}$ of PCR buffer 10X (5 PRIME GmbH, Hamburg, Germany), and $1 \mathrm{U}$ of recombinant Taq DNA polymerase (5 PRIME GmbH, Hamburg, Germany). DNA amplification was performed with the Thermal Cycler 2720 (Applied Biosystems, Europe) at the following temperature profiles: initial denaturation at $95^{\circ} \mathrm{C}$ for 5 minutes, denaturation at $95^{\circ} \mathrm{C}$ for 30 seconds, annealing at $58^{\circ} \mathrm{C}$ for 30 seconds, extension at $72^{\circ} \mathrm{C}$ for 30 seconds, and repeated for 35 cycles, with a final extension for 7 minutes at $72^{\circ} \mathrm{C}$. The partial $18 \mathrm{~S}$ rRNA gene (666 bp) for Hepatozoon canis was amplified by using conventional PCR analysis in a final volume of $50 \mu \mathrm{L}$, containing $5 \mu \mathrm{L}$ of DNA template from each sample, $1 \mu \mathrm{L}(10 \mathrm{pmol} / \mu \mathrm{l})$ of each of the primers, HEP-F and HEP-R, $1 \mu \mathrm{L}(10 \mathrm{pmol} / \mu \mathrm{l})$ of dNTPs (Roche Diagnostics, GmbH, Mannheim, Germany), $5 \mu \mathrm{L}$ of PCR buffer 10X (5 PRIME GmbH, Hamburg, Germany), and $1 \mathrm{U}$ of recombinant Taq DNA polymerase (5 PRIME GmbH, Hamburg, Germany). DNA amplification was performed with the Thermal Cycler 2720 (Applied Biosystems, Europe) at the following temperature profiles: initial denaturation at $95^{\circ} \mathrm{C}$ for 5 minutes, denaturation at $95^{\circ} \mathrm{C}$ for 30 seconds, annealing at $53^{\circ} \mathrm{C}$ for 30 seconds, extension at $72^{\circ} \mathrm{C}$ for 30 seconds, and repeated for 35 cycles, with a final extension for 7 minutes at $72^{\circ} \mathrm{C}$.

DNA electrophoresis for amplicons detection was carried out in 2.2\% FlashGel System (Lonza, Rockland, ME USA), and DNA fragments were visualized. For subsequent sequencing of Babesia spp. and Hepatozoon spp. positive samples, amplification product from PCR was submitted for direct sequencing.

Rickettsia positive samples by qPCR for $16 \mathrm{~S}$ gene were also amplified for the OmpA gene by a conventional PCR for further molecular characterization [13,14]. The partial OmpA gene for Rickettsia spp was amplified by PCR in a final volume of $50 \mu \mathrm{L}$, containing $5 \mu \mathrm{L}$ of DNA template from each sample, $1 \mu \mathrm{L}(10 \mathrm{pmol} / \mu \mathrm{l})$ of each of the primers, 107F and 299R $1 \mu \mathrm{L}(10 \mathrm{pmol} / \mu \mathrm{l})$ of dNTPs (Roche Diagnostics, GmbH, Mannheim, Germany), $5 \mu \mathrm{L}$ of PCR buffer 10X (5 PRIME GmbH, Hamburg, Germany), and $1 \mathrm{U}$ of recombinant Taq DNA polymerase (5 PRIME GmbH, Hamburg, Germany). DNA amplification was performed with the Thermal Cycler 2720 (Applied Biosystems, Europe) at the following temperature profiles: initial denaturation at $95^{\circ} \mathrm{C}$ for 5 minutes, denaturation at $95^{\circ} \mathrm{C}$ for 30 seconds, annealing at $54^{\circ} \mathrm{C}$ for 30 seconds, extension at $72^{\circ} \mathrm{C}$ for 30 seconds, and repeated for 35 cycles, with a final extension for 7 minutes at $72^{\circ} \mathrm{C}$.

The samples were sequenced and compared to known sequences deposited in GenBank ${ }^{\odot}$. The sequencing reaction was performed with the Applied Biosystem 3730xI DNA Analyzer on both strands by BMR Genomics srl (Padua, Italy) by using the dideoxychain-termination method [26]. Consensus sequences were aligned [(BIOEDIT version 7.0 (ClustalW)] with known sequences in GenBank ${ }^{\odot}$ using the basic local alignment search tool (BLAST) available from (http://blast.ncbi.nlm.nih.gov/Blast.cgi?PROGRAM= blastn\&PAGE_TYPE=BlastSearch\&LINK_LOC=blasthome).

Sequences were deposited in GenBank ${ }^{\odot}$.

Current Rickettsia infection was considered when dogs were positive to Rickettsia PCR and/or demonstrated seroconversion to $R$. conorii antigen.

\section{Statistical analysis}

For univariate analysis, Chi-square and Fisher's exact tests were used to test for associations between proportions and putative explanatory factors and univariate Odds ratios (OR) were calculated. The differences were considered significant if the $P$-value was $<0.05$. SPSS (IBM, USA) statistical software (version 19) was used for statistical analyses.

\section{Results \\ Dogs}

The dog population characteristics including breed, gender, age and presence or absence of ticks per each group 
are described in Table 1. Statistical associations were found between breed and presence or absence of ticks and febrile versus afebrile group (Table 1).

\section{Serological and PCR results for all pathogens}

The serological results in febrile and afebrile dogs at the time of the first and second visits are shown in Table 2. The total first visit seropositivity rates for $R$. conorii, E. canis, A. phagocytophilum and L. infantum were $44.8 \%$, $48.5 \%, 37.8 \%$ and $17.6 \%$, respectively. The seroconversion results for $R$. conorii, E. canis and A. phagocytophilum antigens in both groups of dogs are displayed in Table 3. The total seroconversion rates for $R$. conorii, E. canis and A. phagocytophilum were $20.7 \%, 14.3 \%$ and $8.8 \%$, respectively. Seroconversion rates for $R$. conorii were significantly higher in febrile dogs when compared with afebrile dogs (Chi-square $=4.070, P=0.0436$ ). The seroconversion rates for $E$. canis and A. phagocytophilum were not different among the groups studied (Table 3).

The total first visit molecular positive rates for Rickettsia spp., E. canis, A. phagocytophilum, A. platys, L. infantum, Babesia spp. and Hepatozoon spp. were 1.8\%, 4.1\%, 0\%, $2.3 \%, 11.1 \%, 2.3 \%$ and $0.6 \%$, respectively. Positive PCR for E. canis (7.1\%), Rickettsia spp. (3\%), Babesia spp. (4\%) and Hepatozoon spp. (1\%) were only found in febrile dogs (Table 4).

Fourteen febrile dogs (31.8\%) were diagnosed with Rickettsia spp. infection based on seroconversion and/ or PCR while only six afebrile dogs $(12.5 \%)$ seroconverted (Chi-square $=5.036 ; P=0.0248 ;$ Fisher's exact test; $P=0.0414)$.

Febrile illness was statistically significant associated with: acute $R$ conorii positive antibody reaction (Chisquare $=10.837$; univariate Odds ratio $=2.944 ; P=0.001$ ); convalescent $R$. conorii positive antibody reaction (Chisquare $=7.312$; univariate Odds ratio $=4.253 ; P=0.001$ ); seroconversion to $R$. conorii (Chi- square $=4.070$; univariate Odds ratio $=2.935 ; P=0.044$ ); $E$. canis positive PCR (Chisquare $=5.236$; univariate Odds ratio $=1.247 ; P$ calculated with Fisher's exact test $=0.042)$; E. canis or Rickettsia or Anaplasma PCRs positive (Chi-square $=6.835$; univariate Odds ratio $=9.793 ; P=0.009$ ); positivity to any tick pathogen
PCRs $($ Chi-square $=10.161$; univariate odds ratio $=13.687$; $P=0.001)$.

Twelve febrile dogs (12.6\%) displayed initial high $R$. conorii antibody titers while only five afebrile dogs (7.1\%) presented initial high $R$. conorii antibody titers (Chi-square $=1.314$; $P=0.252)$. Eleven febrile dogs (25\%) displayed convalescent high $R$. conorii antibody titers while only 4 afebrile dogs (8.3\%) presented convalescent high $R$. conorii antibody titers (Chi-square $=2.860 ; P=0.091$ ).

Five febrile dogs (35.7\%) displayed initial high E. canis antibody titers while none the afebrile dogs $(0.0 \%)$ presented initial high $E$. canis antibody titers (Chi-square = 3.840; $P=0.050)$. Five out of seven febrile dogs $(71.4 \%)$ diagnosed with $E$. canis infection by means of PCR were seronegative $(n=2)$ or presented a low positive antibody titer $(1: 80 ; n=3)$ at the time of illness and seroconverted suggesting acute infection. Only two febrile dogs diagnosed by positive $E$. canis PCR presented an initial high antibody titer (1:1280).

Three out of three febrile dogs (100\%) diagnosed with A. platys infection by means of PCR were seronegative or presented a low positive antibody titer $(1: 80)$ by $A$. phagocytophilum IFA at the time of illness and only one seroconverted suggesting acute infection. Only one febrile dog diagnosed by positive $A$. platys PCR presented high antibody titer (1:1280).

Initial $E$. canis IFA was statistically associated with $A$. phagocytophilum IFA (Chi-square $=93.490 ; P<0.0001$ ).

\section{Co-infections}

Seven febrile dogs diagnosed with Rickettsia spp. infection based on seroconversion and/or PCR presented coinfections with $A$. platys diagnosed by PCR $(\mathrm{n}=2)$, or with $E$. canis diagnosed by seroconversion $(\mathrm{n}=1)$ or with both $E$. canis and A. phagocytophilum diagnosed by seroconversion $(\mathrm{n}=2)$ or with Babesia diagnosed by PCR $(n=2)$. Two afebrile dogs diagnosed with Rickettsia spp infection based on seroconversion presented coinfections with $E$. canis diagnosed by seroconversion $(\mathrm{n}=1)$ and with both $E$. canis and $A$. phagocytophilum diagnosed by seroconversion $(\mathrm{n}=1)$.

Only febrile dogs presented coinfections with more than one pathogen demonstrated by molecular analysis: one coinfected with $R$. conorii and A. platys, one with $E$.

Table 1 Description of dog population characteristics

\begin{tabular}{|c|c|c|c|c|c|c|c|c|}
\hline \multirow[t]{3}{*}{ DOGS } & \multicolumn{2}{|l|}{ BREED } & \multicolumn{2}{|l|}{ GENDER } & \multicolumn{2}{|l|}{$\mathrm{AGE}^{*}$} & \multicolumn{2}{|l|}{ TICKS } \\
\hline & \multicolumn{2}{|l|}{$N=159$} & \multicolumn{2}{|l|}{$N=171$} & \multicolumn{2}{|l|}{$n=161$} & \multicolumn{2}{|l|}{$N=121$} \\
\hline & Mixed & Pure & Male & Female & Young & Adult & Presence & Absence \\
\hline Total & $58 / 159$ (37.1\%) & $101 / 159(63.5 \%)$ & $94 / 171$ (54.9\%) & 77/171 (45\%) & 16/161 (9.9\%) & 145/161 (90\%) & $31 / 121(25.6 \%)$ & $90 / 121(74.3)$ \\
\hline Febrile & $40 / 58^{* *}(68.9 \%)$ & 53/101 (52.4\%) & 40/94 (42.5\%) & 45/77 (58.4\%) & $13 / 16$ (81.2\%) & $85 / 145$ (58.6\%) & $29 / 31^{* * *}(93.5 \%)$ & 46/90 (51.1\%) \\
\hline Afebrile & 18/58 (31\%) & 48/101 (47.5\%) & 54/94 (57.4\%) & $32 / 77(42.8 \%)$ & $3 / 16(18.7 \%)$ & $60 / 145$ (41.3\%) & 2/31 (6.4\%) & 44/90 (48.8\%) \\
\hline
\end{tabular}

${ }^{*}$ For age classification, young was considered as less than 12 months of age and adult was considered as above 12 months of age ${ }^{* *}$ Chi-square $=4.126, P=0.042$ ${ }^{* * *}$ Chi-square $=17.622, P<0.0001$. 
Table 2 Seroreactivity to several tick-borne pathogens antigens in febrile and afebrile dogs at the time of first and second visit

\begin{tabular}{|c|c|c|c|c|c|c|}
\hline \multirow[t]{3}{*}{ Pathogens } & \multicolumn{3}{|c|}{ Initial serology (first visit) } & \multicolumn{3}{|c|}{ Convalescent serology (second visit) } \\
\hline & Febrile & Afebrile & Total & Febrile & Afebrile & Total \\
\hline & $\mathrm{N}=95$ & $\mathrm{~N}=70$ & $N=165$ & $\mathrm{~N}=44$ & $\mathrm{~N}=48$ & $\mathrm{~N}=92$ \\
\hline R. conorii & $53(55.8 \%)^{*}$ & $21(30.0 \%)$ & $74(44.8 \%)$ & $29(65.9 \%)^{* *}$ & $15(31.2 \%)$ & $44(47.8 \%)$ \\
\hline E. canis & $47(50.0 \%)$ & $32(46.4 \%)$ & $79(48.5 \%)$ & $15(34.1 \%)$ & $11(22.9 \%)$ & $26(28.2 \%)$ \\
\hline A. phagocytophilum & $38(40.4 \%)$ & $24(34.3 \%)$ & $62(37.8 \%)$ & $9(20.4 \%)$ & $7(14.6 \%)$ & $16(17.4 \%)$ \\
\hline L. infantum ${ }^{* * *}$ & $20(20.2 \%)$ & $10(14.1 \%)$ & $30(17.6 \%)$ & Not determined & & \\
\hline
\end{tabular}

${ }^{*}$ Chi-square $=10.837, P=0.001 ;{ }^{* *}$ Chi-square $=11.052, P=0.002 ;{ }^{* *}$ Number of febrile dogs was $99 ;$ Number of afebrile dogs was $71 ;$ total number of dogs was 170.

canis and H. canis; one with L. infantum and E. canis, one with $L$. infantum and A. platys and two coinfected with L. infantum and B. vogeli.

\section{Clinical manifestations and clinicopathological abnormalities}

The most common clinical signs and laboratory abnormalities of febrile dogs diagnosed with Rickettsia infection based on seroconversion and/or PCR were fever, lethargy, myalgia, lameness, elevation of $\mathrm{C}$-reactive protein, hypoalbuminemia, thrombocytopenia and mild non-regenerative anemia. However, other less common clinical signs and clinicopathological abnormalities included orchitis, lymphadenomegaly, splenomegaly, abdominal pain/hunched posture, vomiting and diarrhea, hyperglobulinemia, elevation liver enzymes (ALP, AST) and mature neutrophilic leukocytosis.

Anemia was statistically associated with the presence of an initial high $R$. conorii antibody titer (Chi-square $=3.877$; $P=0.049$ ), positive serology for $L$. infantum (Chi-square $=$ 4.229; $P=0.040$ ), positive $E$. canis PCR (Fisher's exact test; $P=0.048)$, with positivity for $E$. canis or Rickettsia or Anaplasma PCR (Chi-square $=4.229 ; P=0.040$ ) and with positivity for any of the pathogens studied by PCR (Chi-square $=4.561 ; P=0.033$ ). Thrombocytopenia was statistically associated with the presence of positive convalescent $R$. conorii antibody titer (Chi-square $=4.227$; $P=0.040$ ), with acute high $E$. canis antibody titer (Chi-square $=10.809 ; P=0.001$ ), with positive convalescent $E$. canis antibody titer (Chi-square $=4.463 ; P=0.035$ ). It was also significantly associated with positive acute $A$. phagocytophilum antibody titer (Fisher's exact test; $P=0.005$ ), with high convalescent $A$. phagocytophilum antibody titers
(Fisher's exact test; $P=0.037$ ), with $E$. canis positive PCR (Fisher's exact test; $P=0.002$ ), with positivity for $E$. canis or Rickettsia or Anaplasma PCR (Chi-square $=9.888 ; P=0.002$ ) and with positivity for any of the pathogens studied by PCR (Chi-square $=14.457 ; \quad P<0.0001$ ). Hemoparasites were not found by blood smear examination in any of the dogs included in the study.

\section{DNA sequences}

The OmpA gene DNA sequences (170 bp) obtained from three Rickettsia positive PCR samples (GenBank ${ }^{\bullet}$ accession numbers KP896303, KP896304 and KP896305) were $100 \%$ identical to several $R$. conorii sequences present in GenBank ${ }^{\oplus}$ (e.g.: GenBank ${ }^{\odot}$ accession number KJ433804 and KF245453). The above OmpA gene DNA sequences were only $95 \%$ identical to the $R$. parkeri sequences present in GenBank ${ }^{\circ}\left(\right.$ GenBank $^{\circ}$ accession number: KJ158741, KJ174528, JQ906784) which were the second BLAST match.

The 18SrRNA gene DNA sequence (412 bp) obtained from four Babesia spp. positive PCR samples (GenBank ${ }^{\circ}$ accession numbers KP896299, KP896300, KP896301 and KP896302) were $100 \%$ identical to the $B$. vogeli sequences present in GenBank $^{\diamond}\left(\right.$ GenBank $^{\odot}$ accession number: HQ148663). The positive amplicon for Hepatozoon spp. PCR was not sequenced due to the low amount of DNA in the sample.

\section{Discussion}

This study demonstrates acute febrile illness associated with natural Rickettsia infection in dogs living in endemic areas of human MSF by means of seroconversion

Table 3 Seroconversion results for R. conorii, E. canis, A. phagocytophilum in febrile and afebrile dogs

\begin{tabular}{|c|c|c|c|}
\hline \multirow[t]{4}{*}{ Pathogens } & \multicolumn{3}{|l|}{ Seroconversion } \\
\hline & \multicolumn{3}{|c|}{ Number of positive dogs (\%, Cl $95 \%)$} \\
\hline & Febrile & Afebrile & Total \\
\hline & $N=44$ & $N=48$ & $N=92$ \\
\hline R. conorii & $13(29.5 \%, 18-44 \%)^{*}$ & $6(12.5 \%, 5-25 \%)$ & $19(20.7 \%, 13-30 \%)$ \\
\hline E. canis** & $7(16.3 \%, 7-29 \%)$ & $6(12.5 \%, 5-25 \%)$ & $13(14.3 \%, 8-22 \%)$ \\
\hline A. phagocytophilum ** & $3(7.0 \%, 1-18 \%)$ & $5(10.4 \%, 4-22 \%)$ & $8(8.8 \%, 4-16 \%)$ \\
\hline
\end{tabular}

${ }^{*}$ Chi-square $=4.070, P=0.0436$; ${ }^{* *}$ Number of febrile dogs was $43 ;$ number of total dogs was 91 . 
Table 4 Molecular prevalence of all pathogens in febrile and afebrile dogs at the first visit

\begin{tabular}{llll}
\hline Pathogens & \multicolumn{3}{l}{ PCR } \\
\cline { 2 - 4 } & $\begin{array}{lll}\text { Febrile } \\
\mathbf{n}=\mathbf{9 9}\end{array}$ & $\begin{array}{l}\text { Afebrile } \\
\mathbf{n}=\mathbf{7 1}\end{array}$ & $\begin{array}{l}\text { Total } \\
\mathbf{n}=\mathbf{1 7 0}\end{array}$ \\
\hline R. conorii & $3(3.0 \%)^{*}$ & $0(0 \%)$ & $3(1.8 \%)$ \\
E. canis & $7(7.1 \%)^{* *}$ & $0(0 \%)$ & $7(4.1 \%)$ \\
A. platys & $3(3.0 \%)$ & $1(1.4 \%)$ & $4(2.3 \%)$ \\
B. vogeli & $4(4.0 \%)$ & $0(0 \%)$ & $4(2.3 \%)$ \\
H. canis & $1(1.0 \%)$ & $0(0 \%)$ & $1(0.6 \%)$ \\
L. infantum & $14(14.1 \%)$ & $5(6.9 \%)$ & $19(11.1 \%)$ \\
\hline${ }^{*}$ All dogs were positive to 16SrRNA and OmpA PCRs; ${ }^{* *}$ Fisher's exact \\
test, $P=0.042$
\end{tabular}

alone and the combination of seroconversion and/or PCR in comparison to an afebrile control group. Since human MSF was first described in 1910 by Conor and Bunch, canine illness associated with naturally occurring $R$. conorii infection has been described in only a few dogs. Rickettsia conorii infection associated with febrile illness was described in three dogs from Sicily by means of seroconversion and PCR [13] and seven dogs from Portugal by serology and PCR [18]. In addition, this study found significantly higher acute and convalescent $R$. conorii antibody titers in febrile dogs when compared with afebrile-control dogs.

Spotted fever group Rickettsia infection have so far only been recognized as causing acute infections in humans and dogs $[1,27]$. Therefore, acute and convalescent antibodies and PCR at the time of diagnosis were employed as diagnostic tools in this study to allow the detection of canine Rickettsia spp. infection. Interestingly, the majority of febrile dogs were diagnosed based on seroconversion to Rickettsia antigen and only three febrile dogs were diagnosed by molecular analysis in agreement with human MSF diagnostic findings [1,28,29]. Molecular detection of Rickettsia spp. such as $R$. conorii in blood appears to be of low to moderate sensitivity in humans $[1,29,30]$ and in dogs [14] as found also in this study. The discrepancy between serological and molecular testing is likely due to the fact that Rickettsia spp. circulate in blood in low numbers during the acute phase of infection $[2,31]$ and are probably rapidly cleared from blood. Accordingly, experimental infections of dogs with $R$. conorii resulted in a short rickettsiemia of 2-10 days post-infection [6,7] which did not recur following immunosuppression [15].

Clinical signs and clinicopathological abnormalities detected in febrile dogs diagnosed with Rickettsia spp. infection based on seroconversion or positive PCR at initial examination were similar to abnormalities associated with SFG rickettsiosis in humans [2,3,32,33] and Rocky Mountain Spotted Fever rickettsiosis in dogs $[34,35]$ and in experimental infections of dogs with $R$. conorii $[6,7]$. The majority of experimentally $R$. conorii infected dogs presented acute fever, anorexia and lethargy [6,7]. In addition, similar clinical signs and clinicopathological abnormalities were detected in three client-owned Yorkshire terriers living in Sicily [13] and in seven client-owned Portuguese dogs [18].

Due to the fact that the majority of febrile dogs with Rickettsia spp. infection were diagnosed by seroconversion and the detection of rickettsiemia was not successful by molecular techniques in the majority of dogs, the Rickettsia species infecting the majority of these dogs remains unclear. It is well known that serological crossreaction exists between different species of Rickettsia [28] and, therefore, $R$. conorii might not be the only pathogen infecting these dogs. However, based on current knowledge, the most likely species infecting dogs is $R$. conorii due to the fact that, so far, only $R$. conorii has been diagnosed by molecular techniques in the Mediterranean region $[13,18]$ in dogs. In addition, the most common Rickettsia pathogen recognized in Sicily in humans and ticks is $R$. conorii [36] including different strains [4,5]. Other Rickettsia species such as $R$. slovaca [5], $R$. africae, R. aeschlimannii [37] and a new spotted fever group Rickettsia [38] have been occasionally found in Sicily in ticks and R. massiliae has been isolated from one human patient [39]. Additionally, three febrile dogs from the present study were diagnosed by DNA amplification and sequencing of $R$. conorii as the most likely infecting pathogen. Moreover, the three previous canine rickettsiosis cases reported in Sicily were diagnosed as $R$. conorii infection as well [13]. However, the pathogenic role of $R$. massiliae might be more important than previously thought and this rickettsia might cause MSF in humans [39-41] and subclinical [6] or febrile illness in dogs [42]. This is due to the facts that a moderate proportion of $R h$. sanguineus ticks are infected with this microorganism [42-46], human cases of this infection have occasionally been reported [39-41] and R. massiliae antibodies are present in dogs [42,47] and humans $[48,49]$. Further studies should try to improve diagnostic techniques to better characterize the species of Rickettsia infecting dogs in Sicily and in the Mediterranean basin.

The findings of Rickettsia seroconversion in afebrile control dogs including healthy dogs suggest that, in some dogs, Rickettsia infection is subclinical. This finding is in agreement with experimental infections [6,7] and previous literature where dogs have been considered only sentinels of this infection [50,51]. Clinical manifestations of $R$. conorii or Rickettsia spp. infections can vary from subclinical to commonly mild disease in humans and other mammals including dogs, as demonstrated in the present study [2].

Serological and molecular positive rates obtained for E. canis, A. phagocytophilum, A. platys, B. vogeli and $L$. 
infantum are similar to previous studies performed in southern Italy [52,53] and other Mediterranean areas [54]. In contrast, there is insufficient information on seroconversion of tick-transmitted pathogens in sick and healthy dogs in endemic areas. Interestingly, higher seroconversions were found with $R$. conorii than with $E$. canis and A. phagocytophilum and $R$. conorii seroconversion was the only infection significantly associated with febrile illness in this study.

In the present study, febrile illness was associated with several tick pathogens and detection of DNA of pathogens was mainly observed in febrile dogs. In addition, coinfections were only detected by molecular techniques in dogs with febrile illness. The pathogenic role of coinfections remains unclear and is scarcely investigated $[55,56]$. However, the findings of this study suggest that coinfections diagnosed by PCR demonstrating active infection might aggravate clinical manifestations as previously reported [55,57].

In this study, the majority of febrile cases were diagnosed as associated with acute $E$. canis infection based on PCR-positive and acute negative or low positive antibody titers and evidence of seroconversion. Interestingly, it is thought that the majority of clinical cases of E. canis infection correspond to the chronic phase of this disease [58-60] while, in our study, clinical signs and laboratory abnormalities were mainly found during acute infections. The association of antibody reactivity found between $E$. canis and A. phagocytophilum is not surprising due to the well-known cross-reaction that occurs between Ehrlichia and Anaplasma species [60]. In the present study, we consider that the A. phagocytophilum positive serological results are most likely due to $A$. platys infection in dogs rather than a true infection with $A$. phagocytophilum due to the fact that only $A$. platys was diagnosed by molecular techniques and the location of tested dogs in Sicily where only A. platys is prevalent in dogs [61].

There is limited clinical knowledge about $B$. vogeli infection in dogs in endemic areas. Babesia vogeli infection is considered to cause subclinical infection or a mild to moderate diseases in some dogs $[24,62,63]$. Surprisingly, in the present study, B. vogeli infection was only detected in febrile dogs while subclinical infection was not evident based on molecular analysis in this study. Unfortunately, Babesia serology and seroconversion were not performed as this could have decreased the number of truly infected dogs diagnosed in this study. Although blood molecular analysis is probably the most sensitive and accurate diagnostic technique for active Babesia infection in dogs [62], it is important to highlight that Babesia parasites were not observed on blood smear examination. Based on the present findings, $B$. vogeli should be included in the differential diagnosis of dogs with febrile illness and blood PCR appears to be the best diagnostic technique to use for its detection.
Hepatozoon canis infections in dogs are frequently subclinical in endemic areas and clinical cases are sporadically reported [64]. Interestingly, in the present study, only one young febrile dog was diagnosed with $H$. canis infection. These findings are unusual due to the fact that higher rates of $H$. canis infection are reported in Mediterranean endemic areas $[54,64,65]$ and that subclinical infections were not found. In addition, the dog with hepatozoonosis was coinfected with an acute $E$. canis infection diagnosed by PCR. Unfortunately, the dog was lost during follow-up and clinical data about response to treatment was lacking. Whether the clinical signs and clinicopathological abnormalities observed were attributed only to $E$. canis infection or to both infections remains unclear and further studies would need to elucidate the role of coinfections and $H$. canis in febrile illness in endemic areas.

\section{Conclusions}

In conclusion, this study demonstrates acute febrile illness associated with natural Rickettsia infection in dogs living in MSF endemic areas based on acute and convalescent antibody titers, seroconversion alone and the combination of seroconversion and PCR. The most common clinical signs and clinicopathological abnormalities were similar to those described in human and canine spotted fever rickettsiosis. Additional febrile illness was associated with $E$. canis infection demonstrated by PCR, and with detection of tick pathogens and co-infection demonstrated by molecular techniques.

\section{Abbreviations}

DNA: Deoxyribonucleic acid; IFA: Immunofluorescence antibody assay; qPCR: Quantitative PCR; MSF: Mediterranean Spotted fever; PCR: Polymerase chain reaction; SFG: Spotted fever group.

\section{Competing interests}

The authors declare that they have no competing interests.

\section{Authors' contributions}

LSG and MGP designed the research study. LSG set up ELISA and IFAs, contributed with data analysis and interpretation and wrote the manuscript. AC coordinated the veterinary clinics enrolled, set up and performed ELISAs and IFAs, contributed with data analysis and interpretation and revised the manuscript. MGP contributed with data analysis and interpretation and revised the manuscript. MC and TF contributed with routine laboratory testing and revised the manuscript. MT performed DNA extraction, real-time PCR and conventional PCR and revised the manuscript. All authors read and approved the final version of the manuscript.

\section{Acknowledgments}

The authors thank all veterinarians and dog owners that contributed to this study. The authors thank also Martina Nicetto for her help on molecular analysis and the staff of Laboratorio Privato di Analisi Veterinarie San Marco (Padua, Italy) for their support to this study. We are grateful to Dr Ruby Chang (Royal Veterinary College) for assistance with statistical analyses. The authors are also grateful to Bayer Animal Health (Germany) and Bayer Italia S.p.A. and Laboratorio Privato di Analisi Veterinarie San Marco (Padua, Italy) for funding this study. Publication fees of this manuscript have been sponsored by Bayer HealthCare - Animal Health division. 
Dr. Laia Solano-Gallego hold a Ramón y Cajal senior researcher contract awarded by the Ministerio de Ciencia e Innovación (Spain) and the European Social Fund.

\section{Author details}

1Departament de Medicina i Cirurgia Animals, Facultat de Veterinària, Universitat Autònoma de Barcelona (UAB), Cerdanyola 08193, Barcelona, Spain. ${ }^{2}$ Royal Veterinary College, University of London, Hatfield, United Kingdom. ${ }^{3}$ Clinica Veterinaria Camagna, Reggio, Calabria, Italy. ${ }^{4}$ Dip.to di Scienze Veterinarie, Polo Universitario Annunziata, Messina, Italy. ${ }^{5}$ Laboratorio Veterinario San Marco, Padova, Italy.

\section{Received: 2 February 2015 Accepted: 23 March 2015} Published online: 10 April 2015

\section{References}

1. Brouqui P, Parola P, Fournier PE, Raoult D. Spotted fever rickettsioses in southern and eastern Europe. FEMS Immunol Med Microbiol. 2007;49(1):2-12.

2. Parola P, Paddock CD, Raoult D. Tick-borne rickettsioses around the world: emerging diseases challenging old concepts. Clin Microbiol Rev. 2005;18(4):719-56.

3. Cascio A, laria C. Epidemiology and clinical features of Mediterranean spotted fever in Italy. Parassitol. 2006;48(1-2):131-3.

4. Giammanco GM, Vitale G, Mansueto S, Capra G, Caleca MP, Ammatuna P. Presence of Rickettsia conorii subsp. israelensis, the causative agent of Israeli spotted fever, in Sicily, Italy, ascertained in a retrospective study. J Clin Microbiol. 2005;43(12):6027-31.

5. Torina A, de Mera IG F, Alongi A, Mangold AJ, Blanda V, Scarlata F, et al. Rickettsia conorii Indian tick typhus strain and R. slovaca in humans, Sicily. Emerg Infect Dis. 2012;18(6):1008-10.

6. Levin ML, Zemtsova GE, Montgomery M, Killmaster LF. Effects of homologous and heterologous immunization on the reservoir competence of domestic dogs for Rickettsia conorii (israelensis). Ticks Tick-borne Dis. 2014;5(1):33-40.

7. Levin ML, Killmaster LF, Zemtsova GE. Domestic dogs (Canis familiaris) as reservoir hosts for Rickettsia conorii. Vector Borne Zoonotic Dis. 2012;12(1):28-33.

8. Delgado S, Carmenes P. Canine seroprevalence of Rickettsia conorii infection (Mediterranean spotted fever) in Castilla y Leon (northwest Spain). Eur J Epidemiol. 1995;11(5):597-600.

9. Mannelli A, Mandola ML, Pedri P, Tripoli M, Nebbia P. Associations between dogs that were serologically positive for Rickettsia conorii relative to the residences of two human cases of Mediterranean spotted fever in Piemonte (Italy). Prev Vet Med. 2003;60(1):13-26.

10. Torina A, Caracappa S. Dog tick-borne diseases in Sicily. Parassitol. 2006:48(1-2):145-7.

11. Estrada-Pena A, Venzal Bianchi JM. Efficacy of several anti-tick treatments to prevent the transmission of Rickettsia conorii under natural conditions. Ann New York Acad Sci. 2006;1078:506-8.

12. Torina A, Vicente J, Alongi A, Scimeca S, Turla R, Nicosia S, et al. Observed prevalence of tick-borne pathogens in domestic animals in Sicily, Italy during 2003-2005. Zoonoses Public Health. 2007;54(1):8-15.

13. Solano-Gallego L, Kidd L, Trotta M, Di Marco M, Caldin M, Furlanello T, et al. Febrile illness associated with Rickettsia conorii infection in dogs from Sicily. Emerg Infect Dis. 2006;12(12):1985-8.

14. Solano-Gallego L, Trotta M, Caldin M, Furlanello T. Molecular survey of Rickettsia spp. in sick dogs in Italy. Zoonoses Public Health. 2008;55(8-10):521-5.

15. Kelly PJ, Matthewman LA, Mason PR, Courtney S, Katsande C, Rukwava J. Experimental infection of dogs with a Zimbabwean strain of Rickettsia conorii. J Trop Med Hyg. 1992;95(5):322-6.

16. Baneth G, Breitschwerdt EB, Hegarty BC, Pappalardo B, Ryan J. A survey of tick-borne bacteria and protozoa in naturally exposed dogs from Israel. Vet Parasitol. 1998;74(2-4):133-42

17. Solano-Gallego L, Llull J, Osso M, Hegarty B, Breitschwerdt E. A serological study of exposure to arthropod-borne pathogens in dogs from northeastern Spain. Vet Res. 2006;37(2):231-44.

18. Alexandre N, Santos AS, Bacellar F, Boinas FJ, Nuncio MS, de Sousa R. Detection of Rickettsia conorii strains in Portuguese dogs (Canis familiaris). Ticks Tick-borne dis. 2011;2(2):119-22.

19. Furlanello T, Fiorio F, Caldin M, Lubas G, Solano-Gallego L. Clinicopathological findings in naturally occurring cases of babesiosis caused by large form Babesia from dogs of northeastern Italy. Vet Parasitol. 2005;134(1-2):77-85.
20. Stillman BA, Monn M, Liu J, Thatcher B, Foster P, Andrews B, et al. Performance of a commercially available in-clinic ELISA for detection of antibodies against Anaplasma phagocytophilum, Anaplasma platys, Borrelia burgdorferi, Ehrlichia canis, and Ehrlichia ewingii and Dirofilaria immitis antigen in dogs. J Am Vet Med Assoc. 2014;245(1):80-6.

21. Riera C, Valladares JE, Gallego M, Aisa MJ, Castillejo S, Fisa R, et al. Serological and parasitological follow-up in dogs experimentally infected with Leishmania infantum and treated with meglumine antimoniate. Vet Parasitol. 1999;84(1-2):33-47.

22. Solano-Gallego L, Trotta M, Razia L, Furlanello T, Caldin M. Molecular survey of Ehrlichia canis and Anaplasma phagocytophilum from blood of dogs in Italy. Ann N Y Acad Sci. 2006;1078:515-8.

23. Solano-Gallego L, Rodriguez-Cortes A, Trotta M, Zampieron C, Razia L, Furlanello T, et al. Detection of Leishmania infantum DNA by fret-based real-time PCR in urine from dogs with natural clinical leishmaniosis. Vet Parasitol. 2007;147(3-4):315-9.

24. Solano-Gallego L, Trotta M, Carli E, Carcy B, Caldin M, Furlanello T. Babesia canis canis and Babesia canis vogeli clinicopathological findings and DNA detection by means of PCR-RFLP in blood from Italian dogs suspected of tick-borne disease. Vet Parasitol. 2008;157(3-4):211-21.

25. Inokuma H, Okuda M, Ohno K, Shimoda K, Onishi T. Analysis of the $18 \mathrm{~S}$ rRNA gene sequence of a Hepatozoon detected in two Japanese dogs. Vet Parasitol. 2002;106(3):265-71.

26. Sanger E, Nicklen S, Coulson AR. DANN sequencing with chain terminating inhibitors. Proc Natl Acad Sci U S A. 1977;74:5463-7.

27. Nicholson WL, Allen KE, McQuiston JH, Breitschwerdt EB, Little SE. The increasing recognition of rickettsial pathogens in dogs and people. Trends Parasitol. 2010;26(4):205-12.

28. Brouqui P, Bacellar F, Baranton G, Birtles RJ, Bjoersdorff A, Blanco JR, et al. Guidelines for the diagnosis of tick-borne bacterial diseases in Europe. Clin Microbiol Infect. 2004;10(12):1108-32.

29. Santibanez S, Portillo A, Santibanez P, Palomar AM, Oteo JA. Usefulness of rickettsial PCR assays for the molecular diagnosis of human rickettsioses. Enferm Infecc Microbiol Clin. 2013;31(5):283-8.

30. Znazen A, Sellami H, Elleuch E, Hattab Z, Ben Sassi L, Khrouf F, et al. Comparison of two quantitative real time PCR assays for Rickettsia detection in patients from Tunisia. PLoS Negl Trop Dis. 2015;9(2):e0003487.

31. Breitschwerdt EB, Levy MG, Davidson MG, Walker DH, Burgdorfer W, Curtis BC, et al. Kinetics of IgM and IgG responses to experimental and naturally acquired Rickettsia rickettsii infection in dogs. Am J Vet Res. 1990;51(8):1312-6.

32. Rovery C, Brouqui P, Raoult D. Questions on Mediterranean spotted fever a century after its discovery. Emerg Infect Dis. 2008;14(9):1360-7.

33. Colomba C, Saporito L, Polara VF, Rubino R, Titone L. Mediterranean spotted fever: clinical and laboratory characteristics of 415 Sicilian children. BMC Infect Dis. 2006;6:60

34. Ober CP, Spaulding K, Breitschwerdt EB, Malarkey DE, Hegarty BC. Orchitis in two dogs with Rocky Mountain spotted fever. Vet Radiol Ultrasound. 2004;45(5):458-65.

35. Gasser AM, Birkenheuer AJ, Breitschwerdt EB. Canine rocky mountain spotted fever: a retrospective study of 30 cases. J Am Anim Hosp Assoc. 2001;37(1):41-8

36. Giammanco GM, Di Rosa S, Ammatuna P, Mansueto P, Micalizzi A, Vitale G. Continous alert for rickettsiosis in Sicily: molecular characterization of Rickettsia sp. obtained from ticks and human beings (1986-2001). New Microbiol. 2005:28(4):377-9.

37. Beninati T, Genchi C, Torina A, Caracappa S, Bandi C, Lo N. Rickettsiae in ixodid ticks, Sicily. Emerg Infect Dis. 2005;11(3):509-11.

38. Eremeeva ME, Stromdahl EY. Short report: New spotted fever group rickettsia in a Rhipicephalus turanicus tick removed from a child in eastern Sicily, Italy. Am J Trop Med Hyg. 2011;84(1):99-101.

39. Vitale G, Mansuelo S, Rolain JM, Raoult D. Rickettsia massiliae human isolation. Emerg Infect Dis. 2006;12(1):174-5.

40. Parola P, Socolovschi C, Jeanjean L, Bitam I, Fournier PE, Sotto A, et al. Warmer weather linked to tick attack and emergence of severe rickettsioses. PLoS Negl Trop Dis. 2008;2(11):e338.

41. Garcia-Garcia JC, Portillo A, Nunez MJ, Santibanez S, Castro B, Oteo JA. A patient from Argentina infected with Rickettsia massiliae. Am J Trop Med Hyg. 2010;82(4):691-2

42. Beeler E, Abramowicz KF, Zambrano ML, Sturgeon MM, Khalaf N, Hu R, et al. A focus of dogs and Rickettsia massiliae-infected Rhipicephalus sanguineus in California. Am J Trop Med Hyg. 2011;84(2):244-9. 
43. Marquez FJ, Rodriguez-Liebana JJ, Soriguer RC, Muniain MA, Bernabeu-Wittel M, Caruz A, et al. Spotted fever group Rickettsia in brown dog ticks Rhipicephalus sanguineus in southwestern Spain. Parasitol Res. 2008;103(1):119-22.

44. Mura A, Masala G, Tola S, Satta G, Fois F, Piras P, et al. First direct detection of rickettsial pathogens and a new rickettsia, 'Candidatus Rickettsia barbariae', in ticks from Sardinia. Italy Clin Microbiol Infect. 2008;14(11):1028-33.

45. Harrus S, Perlman-Avrahami A, Mumcuoglu KY, Morick D, Baneth G. Molecular detection of Rickettsia massiliae, Rickettsia sibirica mongolitimonae and Rickettsia conorii israelensis in ticks from Israel. Clin Microbiol Infect. 2011;17(2):176-80.

46. Sarih M, Socolovschi C, Boudebouch N, Hassar M, Raoult D, Parola P. Spotted fever group rickettsiae in ticks, Morocco. Emerg Infect Dis. 2008;14(7):1067-73.

47. Pons I, Nogueras MM, Sanfeliu I, Ortuno A, Segura F. Serological evidence of infection with Bar29 in dog population of Catalonia, in the northeast of Spain. 5th International Meeting on Rickettsiae and Rickettsial Diseases, Marseille, France. Abstract book. 2008.

48. Cardenosa N, Segura F, Raoult D. Serosurvey among Mediterranean spotted fever patients of a new spotted fever group rickettsial strain (Bar29). Eur J Epidemiol. 2003;18(4):351-6.

49. Bernabeu-Wittel M, del Toro MD, Nogueras MM, Muniain MA, Cardenosa N Segura $\mathrm{F}$, et al. Presence of human past infections due to the Bar29 rickettsial strain in Southern Spain. J Infect. 2006;52(4):e117-9.

50. Ortuno A, Pons I, Nogueras MM, Castella J, Segura F. The dog as an epidemiological marker of Rickettsia conorii infection. Clin Microbiol Infect. 2009;15 Suppl 2:241-2.

51. Segura-Porta F, Diestre-Ortin G, Ortuno-Romero A, Sanfeliu-Sala I, Font-Creus B, Munoz-Espin T, et al. Prevalence of antibodies to spotted fever group rickettsiae in human beings and dogs from and endemic area of Mediterranean spotted fever in Catalonia, Spain. Eur J Epidemiol. 1998;14(4):395-8.

52. Otranto D, Dantas-Torres F. Canine and feline vector-borne diseases in Italy: current situation and perspectives. Parasit Vectors. 2010;3:2.

53. Otranto D, Testini G, Dantas-Torres F, Latrofa MS, Diniz PP, de Caprariis D, et al. Diagnosis of canine vector-borne diseases in young dogs: a longitudinal study. J Clin Microbiol. 2010;48(9):3316-24.

54. Rene-Martellet M, Lebert I, Chene J, Massot R, Leon M, Leal A, et al. Diagnosis and incidence risk of clinical canine monocytic ehrlichiosis under field conditions in Southern Europe. Parasit Vectors. 2015:8(1):3.

55. Rojas A, Rojas D, Montenegro V, Gutierrez R, Yasur-Landau D, Baneth G. Vector-borne pathogens in dogs from Costa Rica: first molecular description of Babesia vogeli and Hepatozoon canis infections with a high prevalence of monocytic ehrlichiosis and the manifestations of co-infection. Vet Parasitol. 2014;199(3-4):121-8.

56. Baneth G, Harrus S, Gal A, Aroch I. Canine vector-borne co-infections: Ehrlichia canis and Hepatozoon canis in the same host monocytes. Vet Parasitol. 2015;208:30-4.

57. Andrade GB, Barreto WT, Santos LL, Ribeiro LR, Macedo GC, Sousa KC, et al Pathology of dogs in Campo Grande, MS, Brazil naturally co-infected with Leishmania infantum and Ehrlichia canis. Rev Bras Parasitol Vet. 2014;23(4):509-15.

58. Harrus S, Kass PH, Klement E, Waner T. Canine monocytic ehrlichiosis: retrospective study of 100 cases, and an epidemiological investigation of prognostic indicators for the disease. Vet Rec. 1997;141(14):360-3.

59. Mylonakis ME, Koutinas AF, Breitschwerdt EB, Hegarty BC, Billinis CD, Leontides LS, et al. Chronic canine ehrlichiosis (Ehrlichia canis): a retrospective study of 19 natural cases. J Am Anim Hosp Assoc. 2004:40(3):174-84.

60. Little SE. Ehrlichiosis and anaplasmosis in dogs and cats. Vet Clin North Am Small Anim Pract. 2010;40(6):1121-40.

61. de la Fuente J, Torina A, Naranjo V, Nicosia S, Alongi A, La Mantia F, et al. Molecular characterization of Anaplasma platys strains from dogs in Sicily,Italy. BMC Vet Res. 2006;2:24.

62. Solano-Gallego L, Baneth G. Babesiosis in dogs and cats-Expanding parasitological and clinical spectra. Vet Parasitol. 2011;181(1):48-60.

63. Salem NY, Farag HS. Clinical, Hematologic, and Molecular Findings in Naturally Occurring Babesia canis vogeli in Egyptian Dogs. Vet Med Internat. 2014;2014:270345.

64. Baneth G. Perspectives on canine and feline hepatozoonosis. Vet Parasitol. 2011;181(1):3-11.

65. Otranto D, Dantas-Torres F, Weigl S, Latrofa MS, Stanneck D, Decaprariis D, et al. Diagnosis of Hepatozoon canis in young dogs by cytology and PCR. Parasit Vectors. 2011:4:55.

\section{Submit your next manuscript to BioMed Central and take full advantage of:}

- Convenient online submission

- Thorough peer review

- No space constraints or color figure charges

- Immediate publication on acceptance

- Inclusion in PubMed, CAS, Scopus and Google Scholar

- Research which is freely available for redistribution 